\title{
Evaluating Company Growth By Excluding The Earnings Report
}

Mohammed Miah, University of Phoenix, USA

Sindy Baca, University of Phoenix, USA

\begin{abstract}
For most financial analyst, the challenge of evaluating growth for a company is multifaceted. The first one has to do with the understanding the trajectory of the growth. In most cases, the growth is evaluated by using the income statement, debt ratio, balance sheet, market share, general market condition, and product cycle (Gibson, 2009; Gitman, 2009). The growth trajectory can also be traced by looking at the management strategies (Mayo, 2007). In this case, none of the numbers in traditional calculations is taken into account and the conclusion on the growth trajectory is estimated simply by evaluating management strategies. In this paper, the authors demonstrate that ignoring traditional calculations is realistic and applicable in evaluating many companies on the way to recovery.
\end{abstract}

Keywords: Evaluating Company Growth; Financial Analyst

\section{INTRODUCTION}

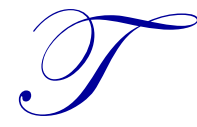

he history of Micron Technology and Rite Aid Corporations will be reviewed, and even though these companies experienced losses over a period of time, these companies are in a new growth trajectory. For example, Micron's management strategies were very effective, not only to keep the company out of bankruptcy but also to lead the company to its long and strong futures. Several of Micron's strategies were analyzed; those strategies include: joint ventures, new product initiatives, and acquisitions. Discussions on these companies' management decisions on their surviving strategies in a long hard down market and their ability to improve market shares are presented. Using short-term market data to predict the future stock price of Micron technology performs an analysis. Finally, the authors claimed that there are many US companies that are emerging from their long hibernation and this is a lifetime chance for investors to identify those companies and monitor their growth.

Financial analyst and the investment bankers routinely evaluate companies for their performance. The tools that they use to assess company performance are the balance sheet, earning report, cash flow, and so on. Among those tools the most favored one seems to be consistent quarterly profitability. However, in spite of positive earning-reports, occasionally the stock prices of some companies have suffered a persistent decline. This is a result of the fact that investment bankers do not just look at the numbers; they also look where the company is going in terms of future performance. In addition, they look at the growth prospect, future market conditions, product cycle that may have an impact on the company's future performance. Provided all of these factors, when a healthy company loses market shares due to market conditions, their earnings decline; consequently, their stock price sufferers often for a long period of time.

The management of those companies often shifts strategies and makes decisions on the basis of new strategies; they try to bring those companies out of their long hibernation. In such a situation those companies fall out of Wall Street's favor and do not make to analysts' recommended lists; as a result, their stock price continues to

decline. The future performance of those companies can still be evaluated by analyzing management's course of actions. In order to do such an analysis, one needs to consider product cycle, mergers and acquisitions, the restructuring plan, and change of leadership. 
In a changing market condition, as a result of the pure competition, occasionally product prices come down and inventories have piled up. This condition can lead to continuous price drop and even push some of the competitors in the sector out of business. This creates a new market condition leaving only few survivors. In other words, once where a pure competition existed, now what can be considered an oligopoly exists, because most of the competitors in the sector are either bankrupt or acquired by few survivors. When pure competition transits to an oligopoly, some survivors get a new infusion and often get ready to come out of their long hibernation. Early detection of such situations can create a lifetime of opportunities for investors who are willing to take calculated risks for investments. The investors can consider risk-benefit analysis to invest in those re-emerging companies. Two of such companies, Micron Technology and Rite Aid Corporations are used in this article as illustration.

\section{PROFILE AND BACKGROUND}

Micron Technology, Inc. manufactures and markets semiconductor devices worldwide, the company was founded in 1978 and is based in Boise, Idaho. One of the main innovations at Micron Technology, Inc. is the dynamic random access memory (DRAM) products, which includes DDR2 and DDR3. These two products are used in the main memory system in computers and servers. There is an array of specialty DRAM memory products that are used in laptop computers, tablets, and other consumer devices (Micron Technology, 2013).

In addition to the DRAM products, Micron Technology, Inc. also offers NAND flash memory products. These include SSD (solid-state drives), flash memory cards, CompactFlash and memory stick products, SD memory cards, and JumpDrive products used in mobile phones, MP3/4 and other consumer applications. Another avenue of income for Micron Technology, Inc. is reselling flash memory products that it purchases from other NAND flash suppliers. In addition, Micron Technology, Inc. provides an electrically re-writeable, nonvolatile semiconductor product named NOR flash memory. NOR flash memory products are used in consumer electronics industrial wired and wireless communications, computing, and automotive applications (Micron Technology, 2013).

Micron Technology, Inc. has a diverse marketing plan. The company markets its products to original equipment manufacturers and retailers through several avenues. One of these avenues is an internal sales force. Another method is with independent sales representatives, and distributors. Micron Technology, Inc. also does direct sales through a web-based customer direct sales channel (Micron Technology, 2013).

Rite Aid Corporation operates a chain of retail drugstores in the United States; it was founded in 1927 and is based in Camp Hill Pennsylvania. In each of the drug stores, the company operates a pharmacy where they sell prescription drugs (Rite Aid Corporation, 2013).

Rite Aid sells a various array of merchandise in their stores. These items include over the counter medication, household items, health and beauty products, personal care items, and food and beverages, which are available in each of their stores. Rite Aid Corporation offers these commodities to their customers protected by payors, such as insurance companies, private employers, government agencies, prescription benefit management companies, and other managed care providers. In addition to these products and the pharmacy, Rite Aids also offer photo processing in their stores (Rite Aid Corporation, 2013).

As of June 20, 2013, Rite Aid Corporation operates 4,615 stores in 31 states and Washington D.C. in the United States. One of the biggest changes that Rite Aid Corporation underwent was when Rite Aid expanded dramatically and acquired Thrifty Payless Holdings Inc (Rite Aid Corporation, 1999).

\section{DETECTING RE-EMERGING COMPANIES}

This paper proposes that acquisitions, mergers, and new product cycles are the major indicators for detecting the re-emergence of companies. Two examples discussed in this paper are Micron Technology and Rite Aid corporations. These companies are in two different sectors. Micron Technology is in technology sector and Rite Aid is in retail drug sector. Micron is the producer and supplier of flash memory chips for computers and 10 years ago was one of the Wall Street's darlings. 10 years ago, when the competition in the memory market heated up, the market became purely competitive; not only that, at some point the market in this sector became saturated. 
As a result, the price of memory chips started to fall and inventories started to rise. This price decline, adversely affected the entire industry. The problem became compounded when the demand for PCs was shifted toward tablets and other mobile devices. The effect on the market was so drastic that most of the chip producers could not even survive. Ten years later, there are only three or four major players in the chip-manufacturing sector. Also, those who managed to survive this market downturn did not only acquire the resources of the bankrupt companies, but also had to adapt to the new technologies.

Given the change in the market, Micron's transition is remarkable. A smart move for Micron management was the acquisition of Japanese Bankrupt chip manufacturer, Elpida. Although all flash memory manufacturers are now supply memory modules for mobile devices, the story of Micron Technology is significant in the sense that when the stock price declined 10 years ago from $\$ 80$ a share to little over five dollars a share by the end of 2012, the management continuously struggled to keep the company out of bankruptcy. Many financial analysts published not only lower price projections, but also cut their ratings on the stock price (Leiblein \& Miller, 2003). This earning cut followed by Micron's poor performance, which validated the analyst's prophecies. However, most of the analysts missed the underlying fundamentals that favored Micron's re-emergence. Micron reported earning losses in last eight quarters (Fisher, 2013). Some analyst, however, slowly started to pay attention to Micron especially after the completion of Elpida acquisition. The transaction was completed on July 31, 2013.

As predicted by many (Lo, 2012), this acquisition clearly put the Micron on a different track. Micron also acquired all outstanding shares of Rexchip because Micron will pay $\$ 344$ million to power Semiconductor of Taiwan for the $24 \%$ of the Rexchip's share it owned. Micron will own rest of the shares from acquiring Elpida. In other words, by acquiring Elpida, Micron will also be the new owner of Rexchip who has the replacement value of $\$ 3$ to $\$ 4$ billion (Fisher, 2013), and Micron acquired Rexchip and its parent major shareholder for \$2.44 billion with total cash outflow of $\$ 946$ million for $\$ 1.075$ billion payment since Yen has depreciated since the agreement. Rest $\$ 1.365$ billion will be paid interest free to the Elpida creditors in six annual payments.

As these acquisitions were going on, something else happened in the sector: the price of the flash memory chips started to rise. This happened because of the shortage of supply for the flash memory chips in the market as most of the chips manufacturers were out of business. The short supply and higher price of memory chips increased the company's performance expectations, which reflected in the Micron's stock price for last six months. Following Figure 1 clearly indicates the positive price movements.

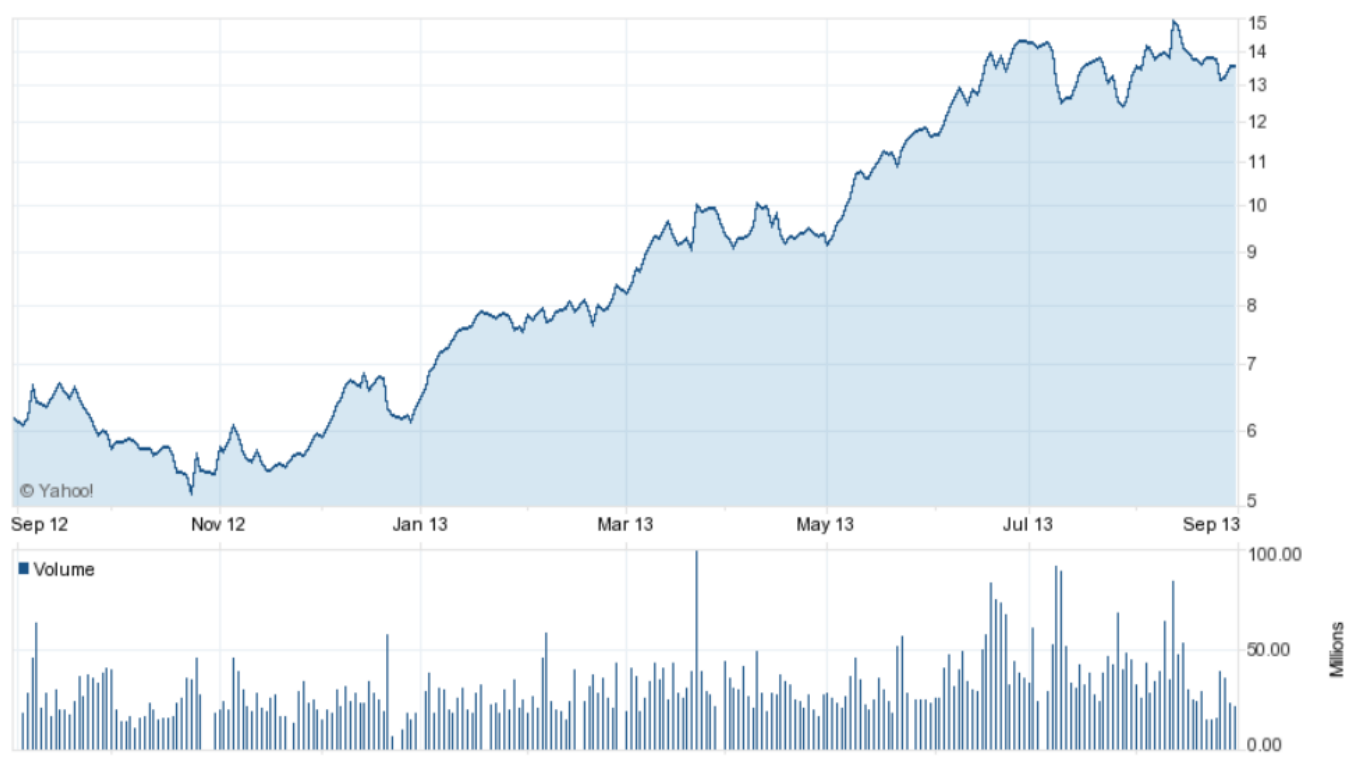

Figure 1: Time Series Graph of the Micro's Stock Price (Micron Technology, 2013) 
Smart investors decided to join the game. Although price was rising consistently the price movement was rocky at best. Some institutional investors failed to see reality in their crystal ball made of simply financial analysis; as a result, shorted the stock each time there was a positive price movement. Nevertheless, the price movement continued since November 2012, which is identified in this article as the inflection point of the time series curve obtained from "Yahoo Finance" page. The above figure shows the price movement of Micron technology. Upward trend is clear from this figure and November 2012 was identified as the inflection point for the price chart. The acquisition of Elpida although was not event free, placed Micron on the second largest chipmakers in the world behind only on Samsung. One important point to consider here is that although Samsung is the world's largest DRAM and NAND memory chips maker, most of its outputs are for Samsung's internal use. In that sense, Micron is now world's largest vender for DRAM and NAND memory chips (Siegel \& Chang, 2009).

In the new market condition, Micron along with two other survivors are now capable of controlling the supply of the memory chips and keep the price at a reasonable level by managing the production level. Last two quarters, the NAND and Flash chips prices are consistently going up and the survivors are reaping the benefit of such a price increase.

The story of Rite Aid is slightly different in the sense that Rite Aid became the victim of the furious competition from its rivals. Their stock prices also suffered a persistent decline from $\$ 70$ a share in 2002 all the way to less than two dollars a share in 2013. However, management took drastic actions by closing out money-losing locations, remodeled the remaining locations, opening new and prospective locations, initiating incentive programs, and relying of high margin generic products. All of these actions cost the company a lot of cash. However, those management actions started to produce positive results. Last quarter, the company reported two cents share profit. Many prudent investors recognized the management course of action, and put their trust back to the management. In last 12 months, the stock price started to rise.

\section{DATA ANALYSIS}

Figure 1 (Micron Technology, 2013) shows the stock price movement of Micron Technology. In the last 12 months, the price has increased more than 100\%. However, it can be viewed that this is just the beginning. A regression line fitted to the daily closing prices data from November 122012 to August 30, 2013. Given the new market condition, and given the fact that new cycle of technology in chip design has started, and given the fact that market has become oligopoly, it would be extremely difficult for the new competition to enter into the market because it will require billions dollars of investment along with latest technological knowledge to enter into the efficient NAND and Flash memory chip design and production. Not only that, by acquiring, Elpida, a Japanese bankrupt chipmaker, Micron has also become one of the suppliers of Apple computers. There is another story behind it: that story is that Apple's dependencies on its competitors Samsung for parts. Apple wants to reduce its dependency on Samsung not only because Samsung competes with Apple for the same product for which it sells the parts to Apple, but also many lawsuits between these two companies created a hostile relationship between them.

The regression model $y=5.37+.047 x$ fits the time series data from last November 1, 2012 to August 30, 2013 so well that independent variable, which is the time this case, explained over $94 \%$ variability of the price movement. The slope of the regression line is estimated as 0.047 . Under this model, estimated stock price in next six months is $\$ 23.97 \pm 1.29$ and by the September of $2015 \$ 42.56 \pm 1.29$.

In case of Rite Aid, similar results are observed. Figure 2 (* collected from Yahoo finance) shows that price movement of Rite Aids stock for last twelve months. The point of inflection is observed by the end of November 2012. The regression model $y=0.89+.013 x$ fits the time series data from last November 16, 2012 to August 30, 2013 so well that independent variable, which is the time this case, explained over 95\% variability of the price movement. The slope of the regression line is estimated to be .013 . Under this model, estimated stock price in next six months is $\$ 6.1 \pm 0.344$ and by the September of $2015 \$ 21.72 \pm 0.344$. 


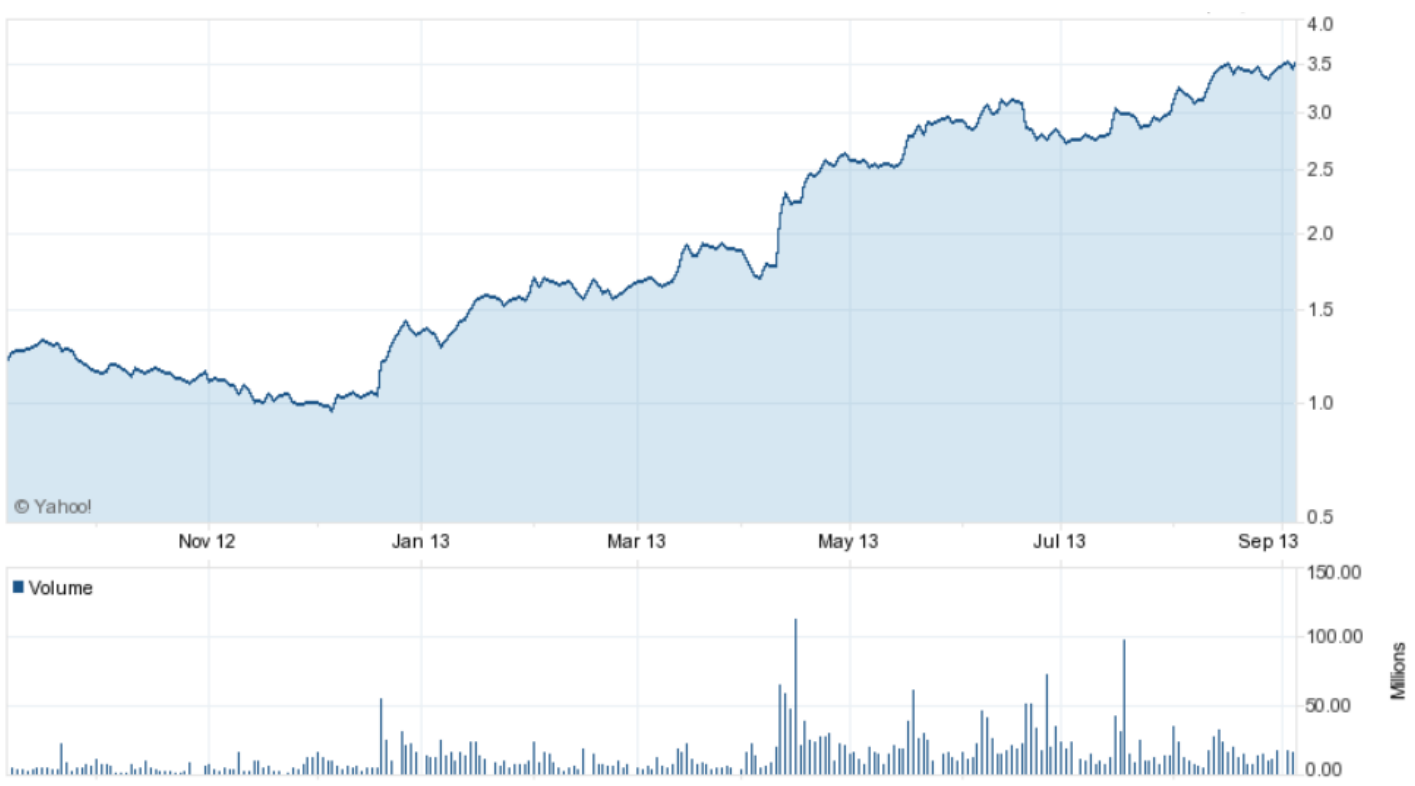

Figure 2: Time Series Graph of the Rite Aid's Stock Price (Rite Aid, 2013)

\section{CONCLUSION}

Point of inflection for the price curve is a valuable tool for aggressive investors. Studying the management strategies, product cycle, market condition and excluding all together the financial information of a company can identify this point. Very few financial analysts are capable of using this technique. The prevailing techniques for choosing the growth stocks are the companies those making money consistently. However the stock price almost always skyrockets when a good company in a growth sector starts generating expected returns quarter after quarter. Predicting market conditions is difficult. It is much easy to fit a mathematical model to a data set after the fact; however, by that time all stock price data becomes available, it is too late for the investors to act. Therefore, it is not an issue of how good the model can predict what has already happened to a stock price; it is rather useful to predict the stock price ahead of time; in that way, individual investors can benefit by investing in re-emerging companies.

\section{DISCLAIMER}

The authors did not receive any compensation from any of the companies mentioned in this article. This article is academic in nature, and therefore is not a buying or selling recommendation. Authors may have positions in the companies mentioned in the article.

\section{AUTHOR INFORMATION}

Mohammed Miah, Ph.D., College Chair, College of Humanities \& Sciences, Las Vegas Campus, University of Phoenix, USA. E-mail: Mohammed.Miah@Phoenix.edu (Corresponding author)

Sindy Baca, Ph.D., Associate Faculty, College of Humanities \& Sciences, Las Vegas Campus, University of Phoenix, USA. E-mail: sindybaca@email.phoenix.edu

\section{REFERENCES}

1. Fisher, R. (2013). Micron: Best of show. Seeking Alpha. Retrieved from http://seekingalpha.com/article/1637922-micron-best-of-show

2. Gibson, C. H. (2009). Financial reporting \& analysis using financial accounting information (11th ed.). Mason, OH: South-Western Cengage Learning. 
3. Gitman, L. J. (2009). Principles of managerial finance (5th ed.). Boston, MA: Pearson Prentice Hall.

4. Leiblein, M. J., \& Miller, D. J. (2003). An empirical examination of transaction-and firm-level influences on the vertical boundaries of the firm. Strategic Management Journal, 24(9), 839-859.

5. Lo, M. A. (2012). A strategic and financial analysis of the DRAM industry. (Doctoral dissertation), Massachusetts Institute of Technology.

6. Mayo, H. B. (2007). Basic finance (9th ed.). Mason, OH: Thomson Higher Education.

7. McGee, P. (2012, Nov 27). Amazon taps bond market. Wall Street Journal. Retrieved from http://search.proquest.com/docview/1201851673?accountid=458

8. Micron Technology. (MU) (2013). Profile, business summary. Yahoo!Finance. Retrieved from http://finance.yahoo.com/q/pr?s=MU

9. Rite Aid Corporation. (RAD) (2013). Profile, business summary. Yahoo!Finance. Retrieved from http://finance.yahoo.com/q/pr?s=RAD

10. Rite Aid Corporation. (1999). In D. Craft \& A. Quick (Eds.), Company profiles for students (Vol. 2, pp. 1107-1111). Detroit: Gale. Retrieved from http://go.galegroup.com.ezproxy.apollolibrary.com/ps/i.do?id= GALE\%7CCX3427200230\&v=2.1\&u=uphoenix\&it=r\&p=GVRL\&sw=w

11. Siegel, J. I., \& Chang, J. J., Samsung electronics. Harvard Business School, 2009.

12. Vogelstein, F. (2003). Mighty Amazon. Fortune, 147(10), 60-69. 